\title{
Preparation of Graphene Oxide Stabilized Nickel Nanoparticles with Thermal Effusivity Properties by Laser Ablation Method
}

\author{
Amir Reza Sadrolhosseini, ${ }^{1}$ A. S. M. Noor, ${ }^{1,2}$ Kamyar Shameli, ${ }^{3}$ Alireza Kharazmi, \\ N. M. Huang, ${ }^{5}$ and M. A. Mahdi ${ }^{1,2}$ \\ ${ }^{1}$ Wireless and Photonics Networks Research Center of Excellence (WiPNET), Faculty of Engineering, University Putra Malaysia, \\ 43400 Serdang, Malaysia \\ ${ }^{2}$ Department of Computer and Communication Systems Engineering, Faculty of Engineering, University Putra Malaysia, \\ 43400 Serdang, Malaysia \\ ${ }^{3}$ Department of Chemistry, Faculty of Science, University Putra Malaysia, 43400 Serdang, Malaysia \\ ${ }^{4}$ Department of Physics, Faculty of Science, University Putra Malaysia, 43400 Serdang, Malaysia \\ ${ }^{5}$ Low Dimensional Materials Research Centre, Physics Department, University of Malaya, Malaysia
}

Correspondence should be addressed to A. S. M. Noor; ashuri@upm.edu.my

Received 4 May 2013; Revised 20 August 2013; Accepted 28 August 2013

Academic Editor: Tianxi Liu

Copyright (c) 2013 Amir Reza Sadrolhosseini et al. This is an open access article distributed under the Creative Commons Attribution License, which permits unrestricted use, distribution, and reproduction in any medium, provided the original work is properly cited.

\begin{abstract}
Nickel nanoparticles were dispersed uniformly in a graphene oxide solution, using a laser ablation technique with different ablation times that ranged from 5 to 20 minutes. The results indicate that the nickel nanoparticle sizes inside the graphene oxide decreased, and the volume fraction for the nickel nanoparticles in the graphene oxide increased with an increasing ablation time. Further, using Fourier Transform Infrared Spectroscopy, the nickel nanoparticles in the graphene oxide demonstrate greater stability from possible agglomeration when the nanoparticle was capped with oxygen from the carboxyl group of the graphene oxide. The thermal effusivity of the graphene oxide and nickel nanoparticle graphene oxide composite was measured using a photoacoustic technique. The concentration of graphene oxide shifted from $0.05 \mathrm{mg} / \mathrm{L}$ to $2 \mathrm{mg} / \mathrm{L}$, and the thermal effusivity increased from $0.153 \mathrm{~W} \cdot \mathrm{s}^{1 / 2} \cdot \mathrm{cm}^{-2} \cdot \mathrm{K}^{-1}$ to $0.326 \mathrm{~W} \cdot \mathrm{s}^{1 / 2} \cdot \mathrm{cm}^{-2} \cdot \mathrm{K}^{-1}$. In addition, the thermal effusivity of the nickel nanoparticles graphene oxide composite increased with an increase in the volume fraction of nickel nanoparticles from $0.1612 \mathrm{~W} \cdot \mathrm{s}^{1 / 2} \cdot \mathrm{cm}^{-2} \cdot \mathrm{K}^{-1}$ to $0.228 \mathrm{~W} \cdot \mathrm{s}^{1 / 2} \cdot \mathrm{cm}^{-2} \cdot \mathrm{K}^{-1}$.
\end{abstract}

\section{Introduction}

Nickel nanoparticles (Ni-NPs) have many important applications as catalysts, conducting and magnetic materials [1], and an electrode layer in multilayer ceramic capacitors [2, 3] and have both unique properties and potential applications in a variety of fields, including electronics [4], magnetic [5], energy technology [6], and biomedicine [7]. Ni-NPs can be synthesized using many methods, including photolytic reduction [8], radiolytic reduction [9], sonochemical [10], solvent extraction reduction [11], microemulsion technique [12], polyol method [13], and microwave irradiation [14].

Graphene Oxide (GO) is obtained from the oxidation of graphite crystals, a single-atomic-layered material. It can dissolve and disperse in a variety of solutions including water. GO has more applications for use in composites materials [15], solar cells [16], medicine [17, 18], antibacterial materials [19], and inorganic optoelectronic devices [20]. The GO molecular structure includes hydroxyl (OH-) and epoxy $\left(-\mathrm{COO}^{-}\right)$groups at the basal plane. Further, it also contains carboxyl groups $\left(-\mathrm{COO}^{-}\right)$at the edge of the molecular structure [21, 22]

Metal nanoparticles can improve and modify the physical properties of GO [20] as can be seen in [20] where the alteration of light scattering was achieved allowing an improved absorption of light in the solar cell. Further, Benayad et al. improved the resistivity of GO by the use of metal nanoparticles [23]. 


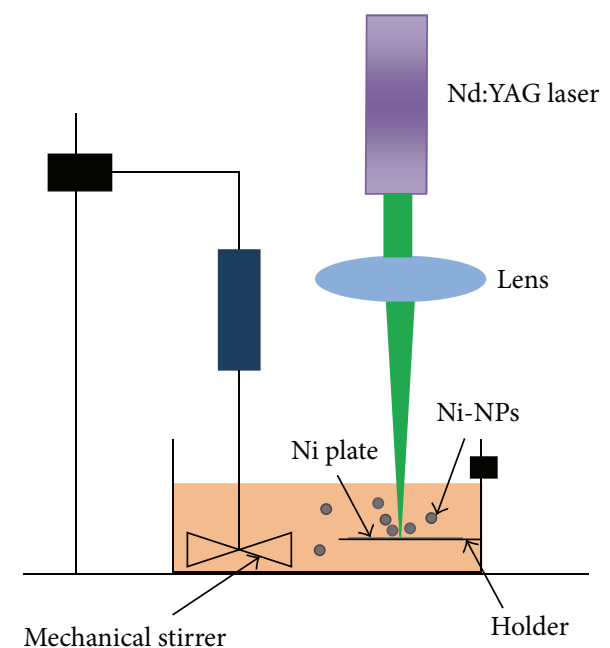

FIGURE 1: Laser ablation setup for preparation of Ni-NPs in the GO solution. The nickel plate is ablated by the tense pulsed laser at different times of 5, 10, 15, and 20 minutes.

A Ni-NPs-GO composite was used as a catalyst for fabrication of carbon nanotube [24] to determine the concentration of glucose in human blood [25], remove and detect aromatic compounds like benzene and toluene in environmental circumstances [26], and develop an electrochemical electrode for sensing carbohydrates [27].

The application of the laser ablation technique offers a novel unique tool for nanofabrication [28]. When the laser ablation is used to produce the metal nanoparticles in an aqueous solution, the nanoparticles are released inside the solution, and nanofluid is formed [29,30]. Metal nanoparticles preparations are relatively difficult to create because they are easily oxidized. The properties of nanoparticles using laser ablation are unique, and they are not reproducible by any other method [31,32]. For example, the fabrication of Ni-NPs in liquid does not require any chemical reduction agent [33], and dimension control is easier than with chemical methods.

The thermal properties are significant to characterize the nanofluid. Thermal effusivity explains the aptness of nanofluid to be able to exchange heat or thermal energy with the environment and measure the thermal impedance of fluids. The relationship between the thermal effusivity $(\varepsilon)$ and the thermal conductivity $(k)$ is given as [34]

$$
\varepsilon=\sqrt{k \rho c_{p}}
$$

where $\rho$ and $c_{p}$ are the density of the sample and specific heat. A photoacoustic (PA) application is used to measure the thermal properties of the nanomaterial, for example, thermal effusivity.

In this study, Ni-NPs was synthesized in GO using laser ablation. The size, shape, distribution, and concentration of Ni-NPs in GO were obtained through transmission electron microscopy (TEM) and atomic absorption spectroscopy (AAS), and the binding of Ni-NPs to GO was analyzed using a Fourier Transform Infrared Spectroscopy (FT-IR). Moreover,

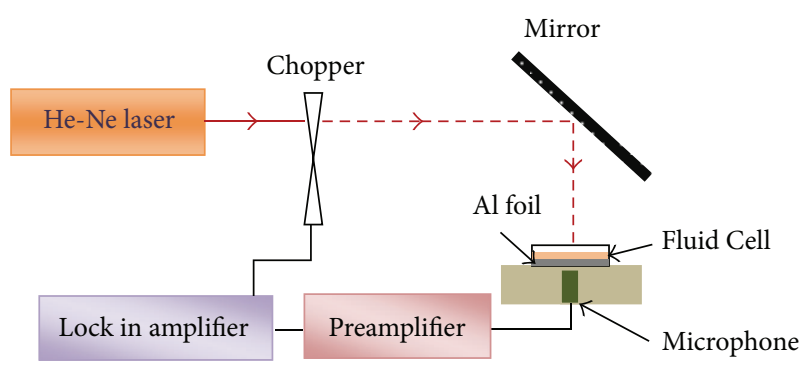

Figure 2: Photoacoustic open cell setup contains a He-Ne laser, a chopper, a mirror, a microphone, a preamplifier, a lock-in amplifier, and a fluid cell.

the thermal effusivity of the GO and Ni-NPs-GO composite was measured using an open cell photoacoustic technique.

\section{Materials and Methods}

2.1. Sample Preparation. The preparation of GO followed the previous reports by Huang et al. [35]. A final concentration of $2 \mathrm{mg} / \mathrm{L} \mathrm{GO}$ in water was used for this study.

Figure 1 shows the schematic diagram for the laser ablation setup. The nickel plate (99.99\% purity; Sigma Aldrich, St. Louis, MO) was immersed in $30 \mathrm{~mL}$ GO and ablated with a pulsed Q-Switched Nd:YAG laser. A pulse duration of $10 \mathrm{~ns}$ and $40 \mathrm{~Hz}$ repetition rate at wavelength $532 \mathrm{~nm}$ with $1200 \mathrm{~mJ}$ power was applied to prepare Ni-NPs in GO solution. During the ablation, a stirrer was used to uniformly disperse the $\mathrm{Ni}$ NPs in GO. The laser beam was focused on the nickel target using a $300 \mathrm{~mm}$ focal length lens. The ablation was carried out at room temperature with different duration times: 5,10 , 15 , and 20 minutes. The nickel nanofluids were characterized using an atomic absorption spectroscopy (AAS, S series), a transmission electron microscopy (TEM, Hitachi H-7100; Hitachi, Chula Vista, CA), and a Fourier Transform Infrared Spectroscopy (FT-IR).

2.2. Photoacoustic Setup. Figure 2 depicts the photoacoustic setup containing a He-Ne laser $(75 \mathrm{~mW}, 632.8 \mathrm{~nm})$, a chopper, a mirror, a fluid cell, a microphone, a preamplifier, and a lock in amplifier. The chopper frequency was controlled by a computer program that shifted from $21 \mathrm{~Hz}$ to $236 \mathrm{~Hz}$.

The bottom of the fluid cell was closed and shut using a $0.017 \mathrm{~mm}$ thick aluminum sheet, and the fluid cell was filled with the nanofluid. To measure thermal effusivity of the $\mathrm{Ni}-$ NPs-GO composite, the photoacoustic signals were detected using an electret microphone, connected to a preamplifier and lock-in amplifier. The phase and amplitude of the signals were registered as a function of a light beam modulation frequency. Measurements were carried out at room temperature for an empty fluid cell and a fluid cell with Ni-NPsGO composite. In order to obtain thermal effusivity, the amplitude of the photoacoustic signal was analyzed using the Rosencwaig-Gersho (RG) theory. 


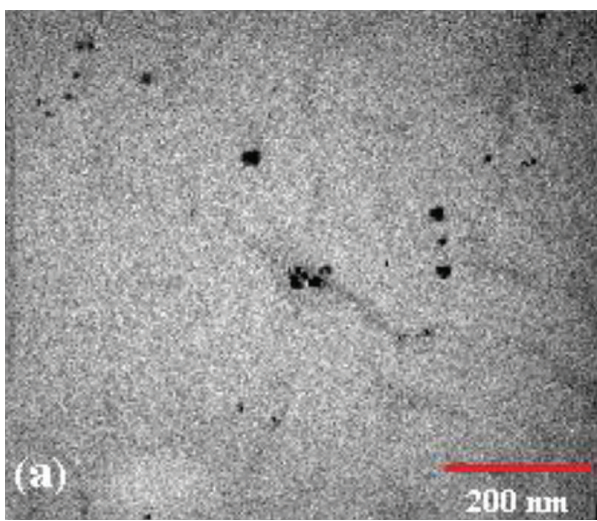

(a)

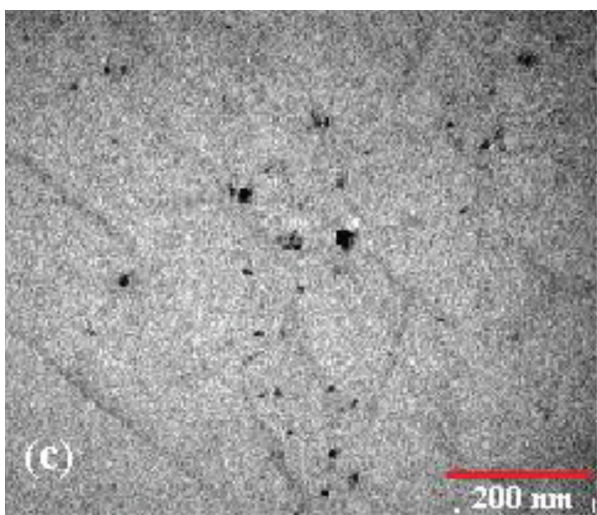

(c)

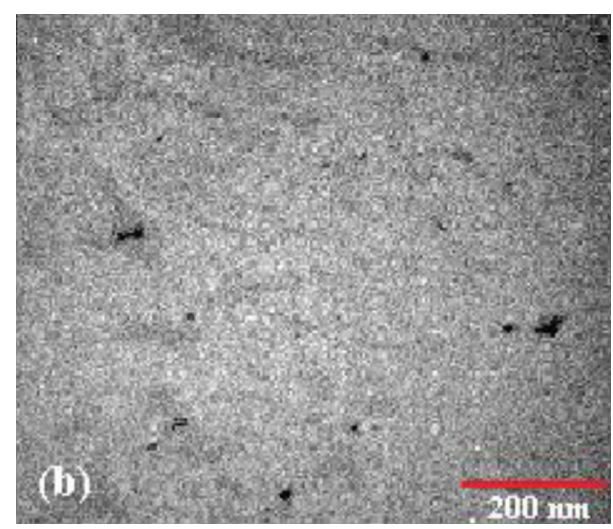

(b)

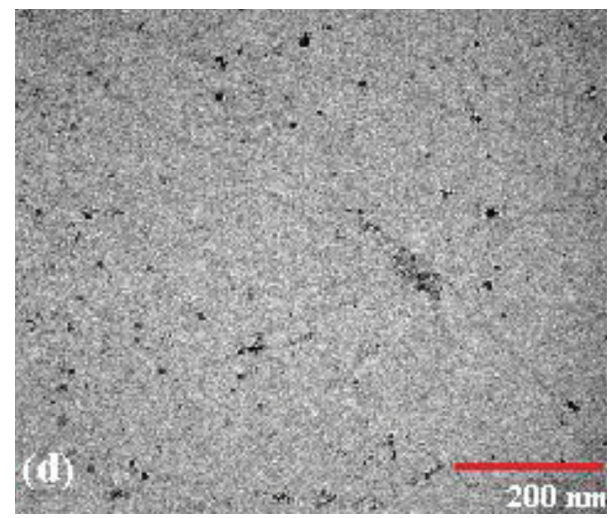

(d)

FIGURE 3: TEM images for Ni-NPs distribution in the GO solution for different ablation times (a) 5 min; (b) 10 min; (c) 15 min; and (d) 20 min.

\section{Results and Discussion}

Figure 3 shows the TEM patterns achieved by using the same accelerating voltage of $120 \mathrm{kV}$, and the patterns explain the shape, particle size, and distribution of Ni-NPs inside the GO. As shown in Figures 3 and 4, the Ni-NPs, which were distributed evenly in the GO, had a spherical shape, and the particle size decreased with an increase of the ablation time. This results is illustrated in Figure 4 which shows that the mean sizes of Ni-NPs in the GO decreased from $15.53 \mathrm{~nm}$ to $6.83 \mathrm{~nm}$. In addition, Figure 4 shows the distribution of NiNPs' increasing with a longer ablation time.

The Ni-NPs concentrations were measured by AAS, and the concentrations increased with increases in the ablation time. Volume fractions $(V)$ were calculated by the following equation:

$$
V=\frac{V_{p}}{V_{p}+V_{L}},
$$

where $V_{L}$ and $V_{p}$ are the volume of liquid and the volume of the particles $(m / \rho$, where $\rho$ and $m$ are the mass density of the nickel and the particles mass dispersed in the GO, resp.). Hence, (3) was derived from a modification of (2) as follows:

$$
V=\frac{C_{\text {Particle }}}{C_{\text {Particle }}+\rho},
$$

TABLE 1: Pertinent parameters of Ni nanoparticles in graphene oxide.

\begin{tabular}{lccc}
\hline Sample & Size $(\mathrm{nm})$ & Concentration $(\mathrm{ppm})$ & Volume fraction \\
\hline $5 \mathrm{~min}$ & 15.53 & 0.9 & $0.101 \times 10^{-6}$ \\
$10 \mathrm{~min}$ & 12.30 & 1.73 & $0.1942 \times 10^{-6}$ \\
$15 \mathrm{~min}$ & 9.76 & 3.23 & $0.3626 \times 10^{-6}$ \\
$20 \mathrm{~min}$ & 6.83 & 4.86 & $0.5456 \times 10^{-6}$ \\
\hline
\end{tabular}

where $C_{\text {Particle }}$ are the concentrations of the Ni-NPs-GO composite obtained from AAS result.

The pertinent parameters are displayed in Table 1.

The FT-IR spectra were recorded to identify capping of the Ni-NPs in the GO. Figure 5 shows the FT-IR spectrum of the GO where plot (a) did not contain any impurity, and plot (b) showed the spectrum containing Ni-NPs dispersed in GO. Both results exhibit the FT-IR spectra of the GO and the NiNPs-GO composite at a frequency range of $4000-300 \mathrm{~cm}^{-1}$. The spectrum in plot (a) shows transmission peaks at 3232 , 2829, 1719, 1611, 1401, 1155, 1029, 856, 564, and $412 \mathrm{~cm}^{-1}$. Similarly, transmission peaks for the Ni-NPs in the GO were obtained at 3218, 2914, 1718, 1595, 1411, 1037, 792, 736, 665, 615, $587,543,438$, and $375 \mathrm{~cm}^{-1}$ for plot (b). The FT-IR spectra of the GO and Ni-NPs/GO hybrid showed the peak at 1719, 1611, and $1401 \mathrm{~cm}^{-1}$ had shifted to 1718,1595 , and $1411 \mathrm{~cm}^{-1}$. 


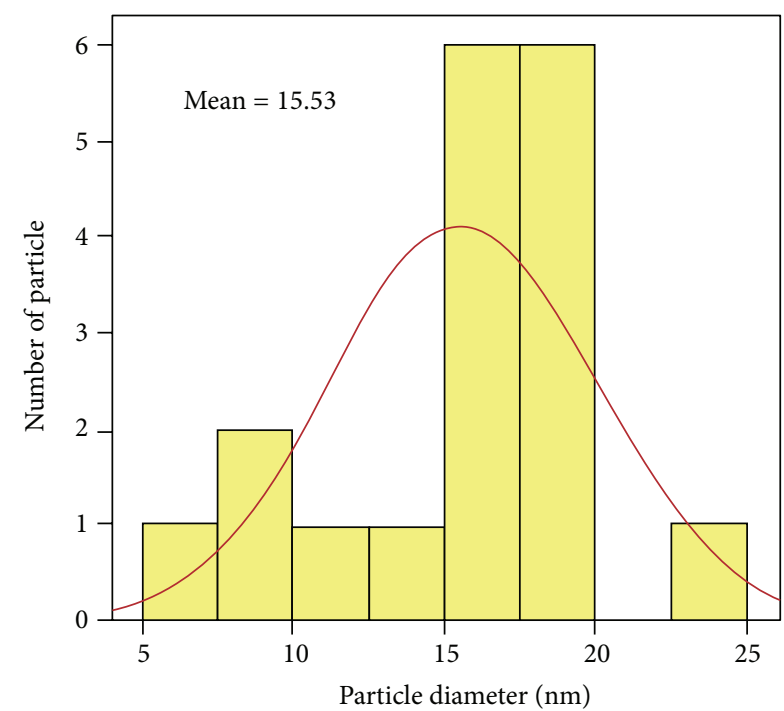

(a)

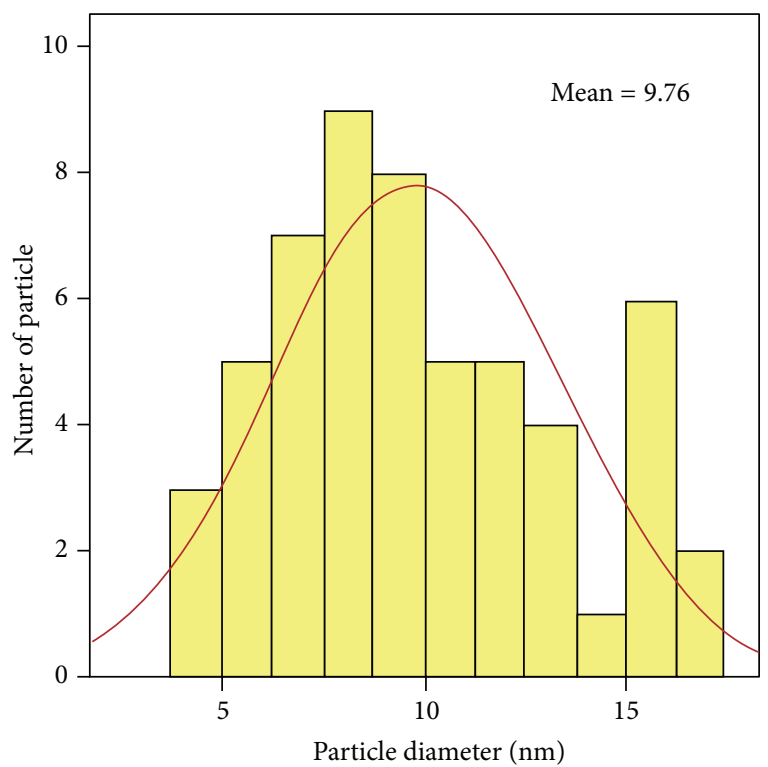

(c)

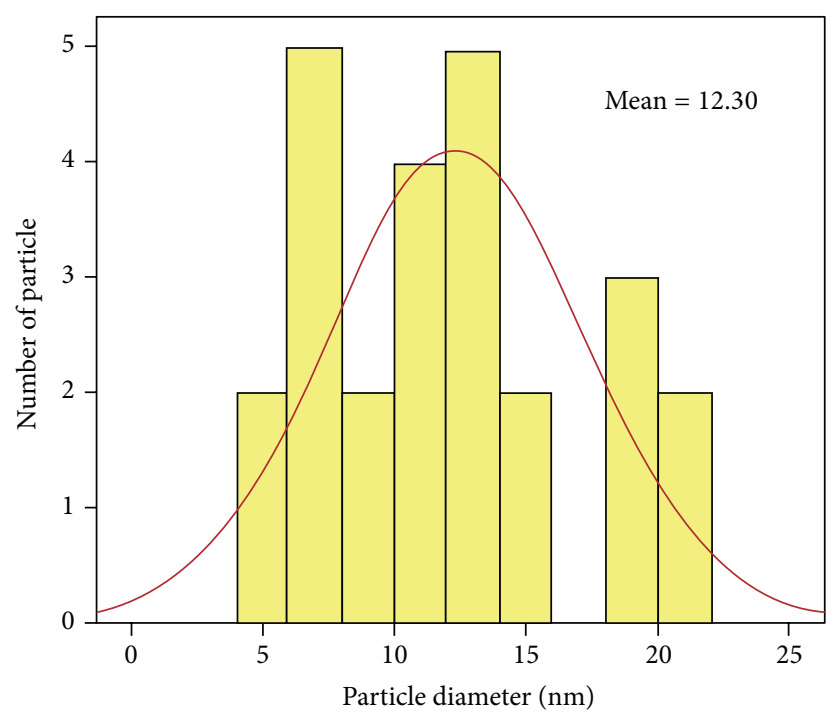

(b)

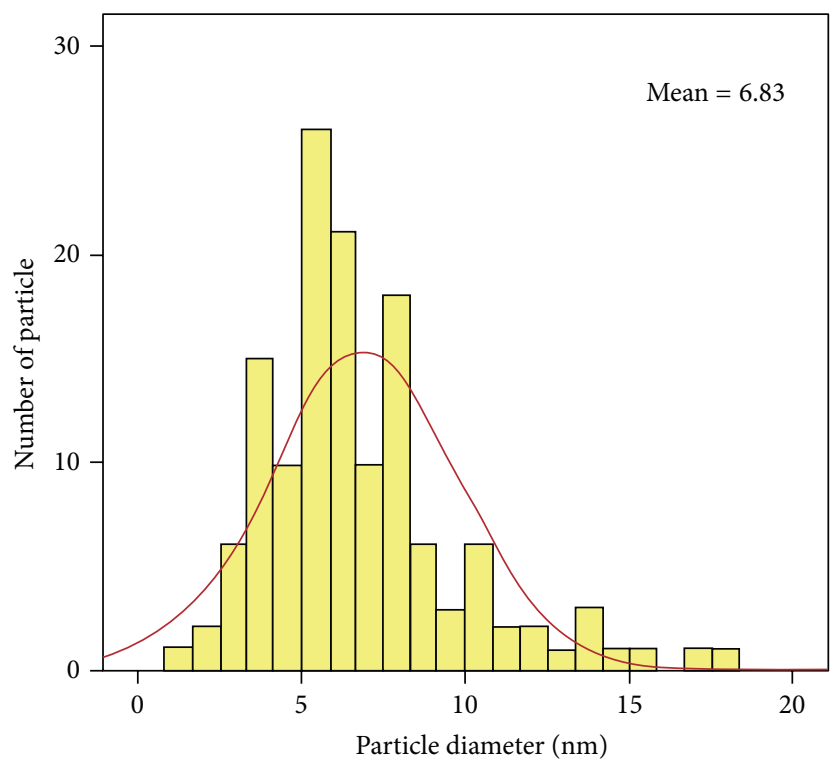

(d)

Figure 4: The distribution of size and the volume concentration of Ni-NPs inside the GO solution were (a) $5 \mathrm{~min}$; (b) $10 \mathrm{~min}$; (c) $15 \mathrm{~min}$; and (d) $20 \mathrm{~min}$.

In Figure 5, the broad peak at 1719 and $1611 \mathrm{~cm}^{-1}$ corresponding to $v(\mathrm{C}=\mathrm{O})$ of $-\mathrm{COOH}$ on the $\mathrm{GO}$ shifts to 1718 and $1595 \mathrm{~cm}^{-1}$ due to the formation of $-\mathrm{COO}^{-}$after coating with Ni-NPs. The characteristic peak corresponding to the stretching vibration of $\mathrm{Ni}-\mathrm{O}$ bond shifts to lower wave number that suggests that $\mathrm{Ni}-\mathrm{NPs}$ are bound to the $-\mathrm{COO}^{-}$ on the GO surface. In plot 5(b), the broad peaks of 792, 736, $665,615,587,543,438$, and $375 \mathrm{~cm}^{-1}$ are related to Van der Waals forces that are bonding with oxygen on the of GO surface with surface charges of Ni-NPs [36]. Consequently, the Ni-NPs were located on the GO surface and between the GO sheets (see Figure 5(c)).
In accordance with RG theory, the amplitude of the photoacoustic signal is inversely proportional to the modulation frequency [36]. The amplitude of pressure fluctuations $(\delta P)$ in the presence of Ni-NPs/GO was calculated as

$$
|\delta P|=\frac{P_{1}}{f^{P_{2}}\left(1+P_{3} / \sqrt{f}+\left(P_{3}^{2}\right) / \sqrt{2 f}\right)^{1 / 2}},
$$

where

$$
P_{3}=\frac{2 \varepsilon_{s}}{\varepsilon_{\mathrm{Al}} l_{\mathrm{Al}}}\left(\frac{\alpha_{\mathrm{Al}}}{\pi}\right)^{1 / 2},
$$




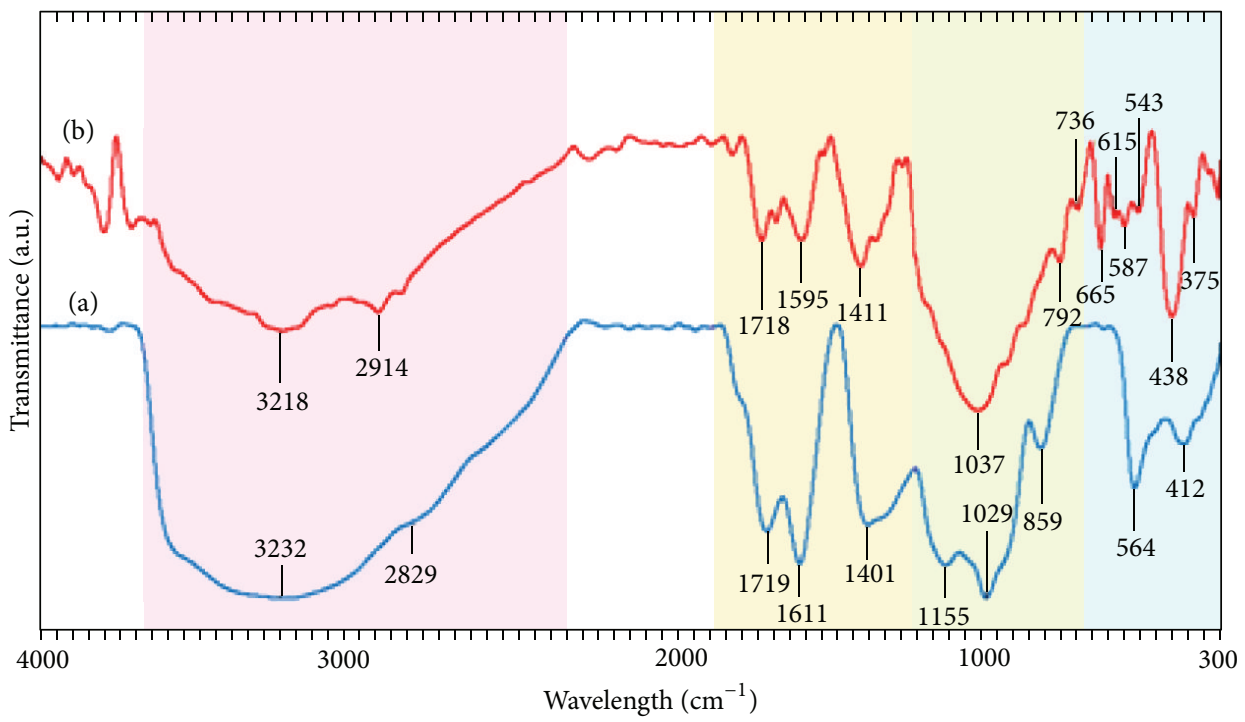

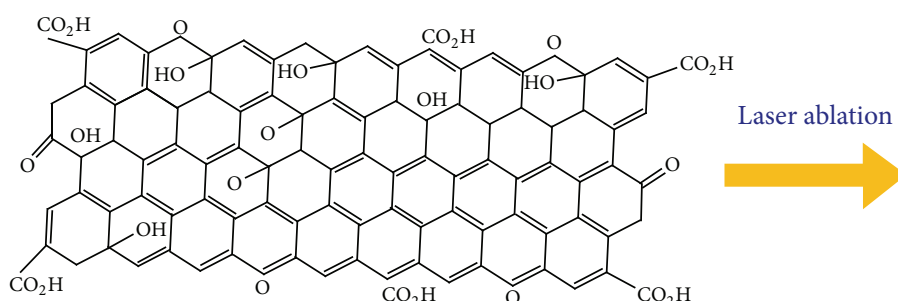

Graphene oxide

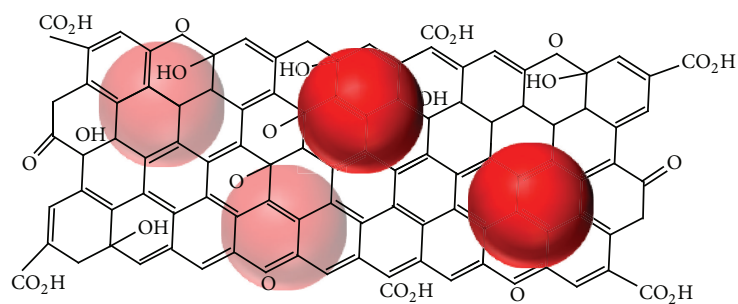

Ni-NPs/GO composite

(c)

FIgURE 5: Plots (a) and (b) show the FT-IR results for pure GO and GO with Ni-NPs, respectively. Plot (c), graphene oxide sheet before and after laser ablation, shows the Ni-NPs located on the surface of the GO and between the GO sheets.

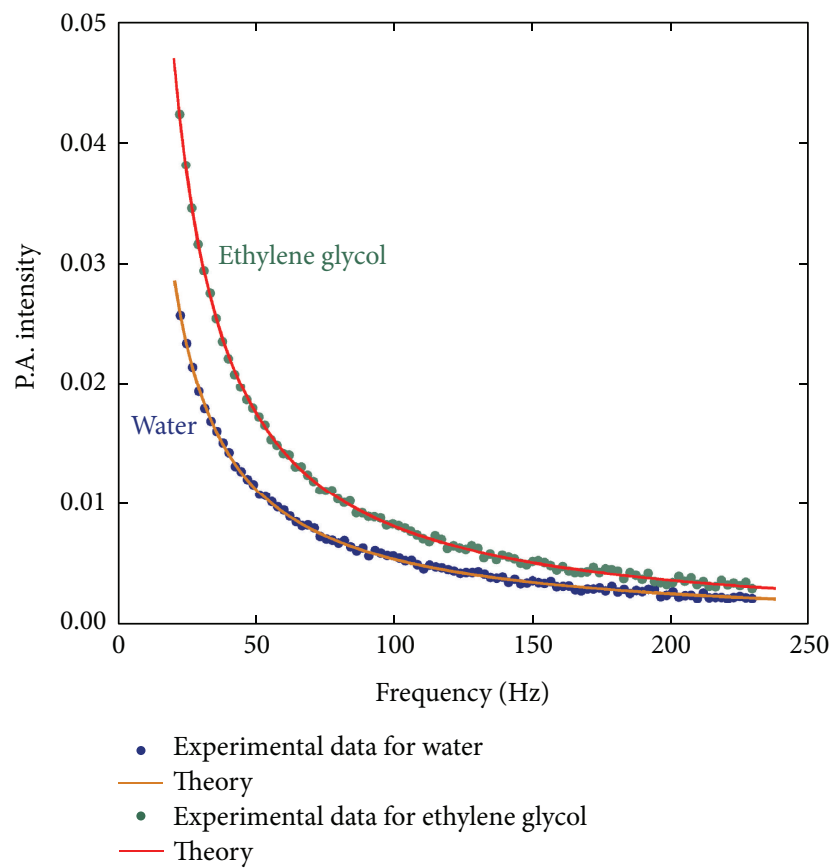

FIGURE 6: Photoacoustic signal to calibrate and test the setup. The thermal effusivity of water and ethylene glycol are 0.1631 and $0.0931 \mathrm{~W} \cdot \mathrm{s}^{1 / 2} \cdot \mathrm{cm}^{-2} \cdot \mathrm{K}^{-1}$, respectively. 

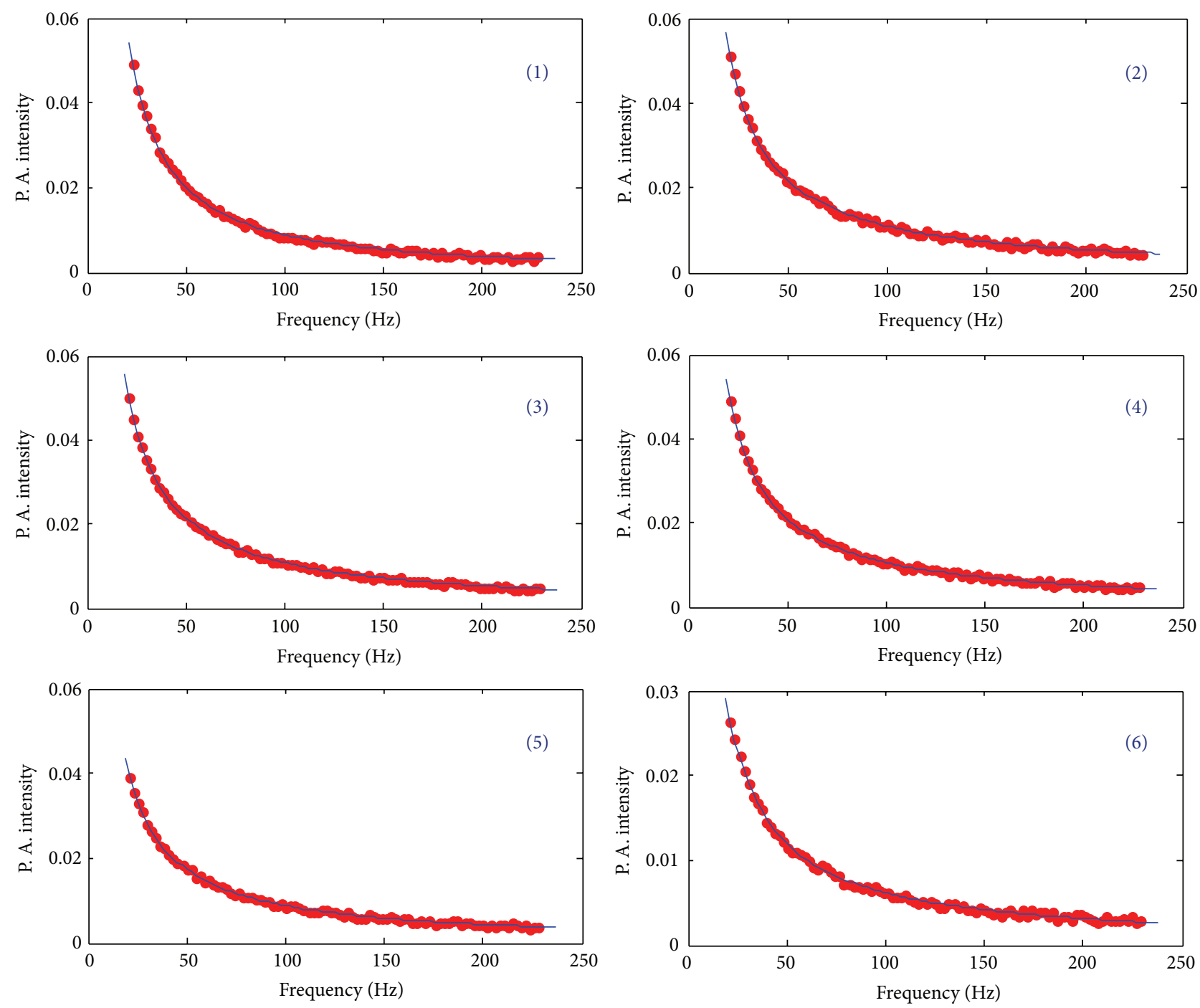

- Experimental data
- Theory

- Experimental data

— Theory

FIGURE 7: Photoacoustic signals for measurement of thermal effusivity of the GO indicate the concentration: (1) $0.05 \mathrm{mg} / \mathrm{L},(2) 0.1 \mathrm{mg} / \mathrm{L},(3)$ $0.3 \mathrm{mg} / \mathrm{L}$, (4) $0.5 \mathrm{mg} / \mathrm{L}$, (5) $0.8 \mathrm{mg} / \mathrm{L}$, and (6) $2 \mathrm{mg} / \mathrm{L}$.

$\alpha_{\mathrm{Al}}, \varepsilon_{\mathrm{Al}}$, and $l_{\mathrm{Al}}$ are the thermal diffusivity, thermal effusivity, and thickness of the aluminium foil. To measure the thermal effusivity of the GO and Ni-NPs/GO composite, $P_{1}$ and $P_{2}$ have to obtain from the $\mathrm{Al}$ foil signal as a function of modulation frequency. Adjustable parameters $\left(P_{1}\right.$ and $\left.P_{2}\right)$ must be calculated by fitting the former data to [34]

$$
\left|\delta P_{\mathrm{Al}}\right|=P_{1} f^{P_{2}}
$$

The experiment was carried out with deionized (DI) water and ethylene glycol to calibrate the setup (see Figure 6).

The measurement of thermal effusivity was done for the $\mathrm{GO}$ and $\mathrm{Ni}-\mathrm{NPs} / \mathrm{GO}$ composite with different concentration of GO and Ni-NPs, respectively. The photoacoustic signals used for measuring of thermal effusivity are depicted in Figures 7 and $8 . \varepsilon_{a}, l_{\mathrm{Al}}$, and $\alpha_{\mathrm{Al}}$ are $2.36 \mathrm{~W} \cdot \mathrm{s}^{1 / 2} \cdot \mathrm{cm}^{-2} \cdot \mathrm{K}^{-1}$,
$0.0017 \mathrm{~cm}$, and $0.99 \mathrm{~cm}^{2} / \mathrm{s}$, respectively, and the results are further sorted in Table 2.

The concentration of the GO solution was shifted from $0.1 \mathrm{mg} / \mathrm{L}$ to $2 \mathrm{mg} / \mathrm{L}$, and the thermal effusivity of the GO solution increased when increasing the concentration of the GO from $0.153 \mathrm{~W} \cdot \mathrm{s}^{1 / 2} \cdot \mathrm{cm}^{-2} \cdot \mathrm{K}^{-1}$ to $0.326 \mathrm{~W} \cdot \mathrm{s}^{1 / 2} \cdot \mathrm{cm}^{-2} \cdot \mathrm{K}^{-1}$ (Figure 9(a)). The variation in the thermal effusivity of the Ni-NPs/GO composite is shown in Figure 9(b), enhanced by increasing the volume fraction of Ni-NPs from $0.1612 \mathrm{~W} \cdot \mathrm{s}^{1 / 2} \cdot \mathrm{cm}^{-2} \cdot \mathrm{K}^{-1}$ to $0.228 \mathrm{~W} \cdot \mathrm{s}^{1 / 2} \cdot \mathrm{cm}^{-2} \cdot \mathrm{K}^{-1}$. The thermal effusivity concept is an exchange of heat with the environment. The effective nanofluid surface expanded by increasing the volume fraction, and the ability of the nanofluid to exchange heat with the environment was enhanced, when the volume fraction increased, causing an increase in the thermal effusivity of the Ni-NPs-GO composite. 

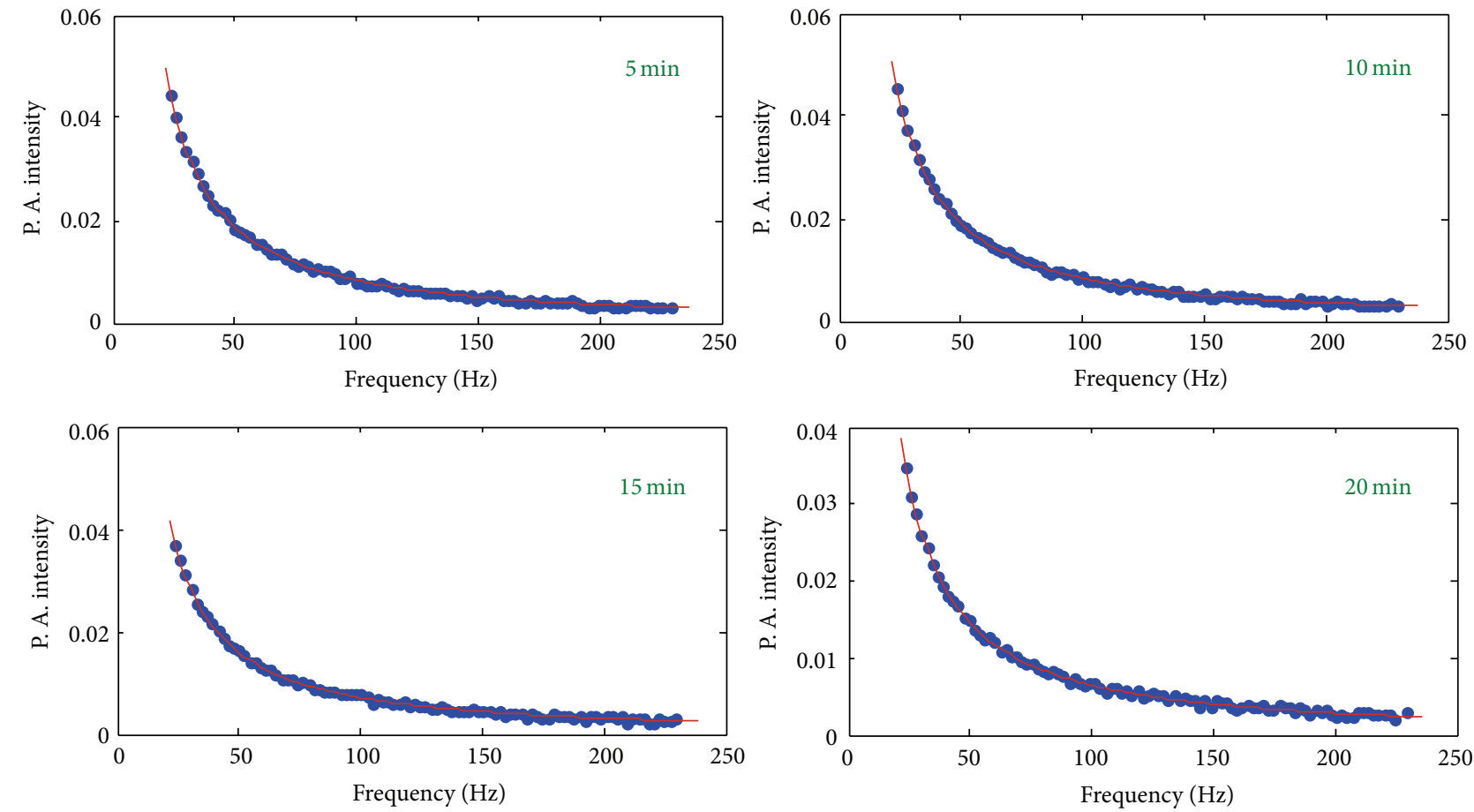

- Experimental data

- Experimental data

- Theory

— Theory

FIGURE 8: Photoacoustic signals for Ni-NPs-GO composite with different ablation times are displayed.

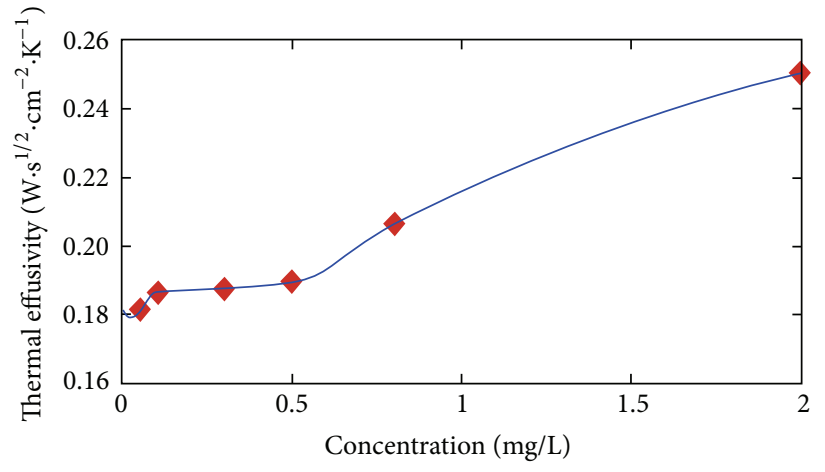

(a)

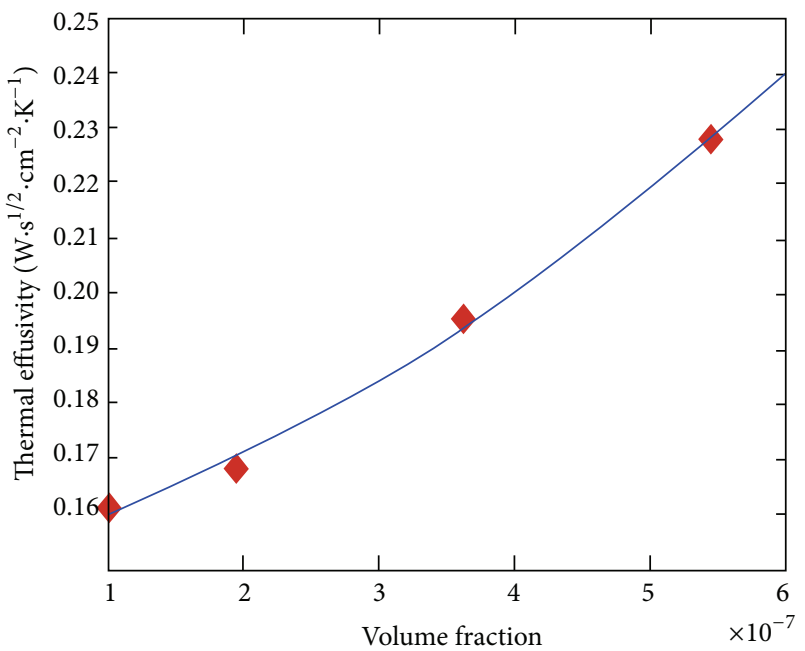

(b)

FIGURE 9: Variation of thermal effusivity versus (a) concentration of GO and (b) volume fraction of Ni-NPs in graphene oxide.

\section{Conclusions}

The Ni-NPs were synthesized in the GO using the laser ablation method. The binding between the carboxyl groups $\left(-\mathrm{COO}^{-}\right)$on the GO and Ni-NPs occurred and achieved via FT-IR spectroscopy. The particle sizes of $15.53,12.30,9.76$, and $6.83 \mathrm{~nm}$ were obtained in $5,10,15$, and 20 minutes ablation times, respectively. The GO controls the particle size and shape and prevents agglomeration between the ablated $\mathrm{Ni}$ NPs. Hence, the Ni-NPs stay completely stable for a long time, and with an increase in the ablation time, the particle size reduces, and both absorption and volume fraction increase.

Consequently, laser ablation is an environmentally friendly, simple, and green method for preparation of $\mathrm{Ni}-\mathrm{NPs}$ in the GO. Moreover, the photoacoustic signals can be registered for a determination of thermal effusivity of 
TABLE 2: Pertinent parameters of the GO and Ni-NPs/GO composite for measuring thermal effusivity.

\begin{tabular}{lcc}
\hline Sample & $P_{3}$ & $\varepsilon_{s}\left(\mathrm{~W} \cdot \mathrm{s}^{1 / 2} \cdot \mathrm{cm}^{-2} \cdot \mathrm{K}^{-1}\right)$ \\
\hline Water & 45.631 & 0.163 \\
Ethylene glycol & 26.038 & 0.093 \\
$\mathrm{GO}$ & & \\
$\quad 0.05 \mathrm{mg} / \mathrm{L}$ & 43.064 & 0.153 \\
$0.1 \mathrm{mg} / \mathrm{L}$ & 46.578 & 0.166 \\
$0.3 \mathrm{mg} / \mathrm{L}$ & 47.457 & 0.169 \\
$0.5 \mathrm{mg} / \mathrm{L}$ & 48.791 & 0.174 \\
$0.8 \mathrm{mg} / \mathrm{L}$ & 60.731 & 0.216 \\
$2 \mathrm{mg} / \mathrm{L}$ & 91.474 & 0.326 \\
$\mathrm{Ni}-\mathrm{NPs}$ & & \\
$5 \mathrm{~min}$ & 45.127 & 0.161 \\
$10 \mathrm{~min}$ & 47.125 & 0.168 \\
$15 \mathrm{~min}$ & 54.725 & 0.195 \\
$20 \mathrm{~min}$ & 63.792 & 0.228 \\
\hline
\end{tabular}

the Ni-NPs/GO composite. The results show that with an increasing volume fraction of $\mathrm{Ni}$ nanofluid, the thermal effusivity does increase.

\section{Acknowledgments}

The authors acknowledge Universiti Putra Malaysia for the fund from the Research University Grant Scheme (05-0212-2015RU/05-01-12-1626RU/05-01-12-1627RU) and the postdoctoral fellowship under the Wireless and Photonics Network Research Centre (WiPNet).

\section{References}

[1] S. H. Wu and D. H. Chen, "Synthesis and characterization of nickel nanoparticles by hydrazine reduction in ethylene glycol," Journal of Colloid and Interface Science, vol. 259, no. 2, pp. 282286, 2003.

[2] W. Wang, Y. Itoh, I. Lenggoro, and K. Okuyama, "Nickel and nickel oxide nanoparticles prepared from nickel nitrate hexahydrate by a low pressure spray pyrolysis," Materials Science and Engineering B, vol. 111, no. 1, pp. 69-76, 2004.

[3] R. Eluri and B. Paul, "Microwave assisted greener synthesis of nickel nanoparticles using sodium hypophosphite," Materials Letters, vol. 76, pp. 36-39, 2012.

[4] W. Tseng and C. Chen, "Dispersion and rheology of nickel nanoparticle inks," Journal of Materials Science, vol. 41, no. 4, pp. 1213-1219, 2006.

[5] S. P. Gubin, Y. A. Koksharov, G. B. Khomutov, and G. Y. Yurkov, "Magnetic nanoparticles: preparation, structure and properties," Russian Chemical Reviews, vol. 74, no. 6, pp. 489520, 2005.

[6] R. Karmhag, T. Tesfamichael, E. Wäckelgard, G. Niklasson, and M. Nygren, "Oxidation kinetics of nickel particles: comparison between free particles and particles in an oxide matrix," Solar Energy, vol. 68, no. 4, pp. 329-333, 2000.

[7] S. R. Llamazares, J. Merchá, I. Olmedo et al., "Ni/Ni oxides nanoparticles with potential biomedical applications obtained by displacement of a nickel-organometallic complex," Journal of Nanoscience and Nanotechnology, vol. 8, no. 8, pp. 3820-3827, 2008.

[8] F. Alonso, P. Riente, J. A. Sirvent, and M. Yus, "Nickel nanoparticles in hydrogen-transfer reductions: characterisation and nature of the catalyst," Applied Catalysis A, vol. 378, no. 1, pp. 42-51, 2010.

[9] S. Remita, M. Mostafavi, and M. O. Delcourt, "Bimetallic Ag$\mathrm{Pt}$ and Au-Pt aggregates synthesized by radiolysis," Radiation Physics and Chemistry, vol. 47, no. 2, pp. 275-279, 1996.

[10] Y. Mizukoshi, K. Okitsu, Y. Maeda, T. A. Yamamoto, R. Oshima, and Y. Nagata, "Sonochemical preparation of bimetallic nanoparticles of gold/palladium in aqueous solution," Journal of Physical Chemistry B, vol. 101, no. 36, pp. 7033-7037, 1997.

[11] M. Brust, M. Walker, D. Bethell, D. J. Schiffrin, and R. Whyman, "Synthesis of thiol-derivatised gold nanoparticles in a twophase liquid-liquid system," Journal of the Chemical Society, Chemical Communications, no. 7, pp. 801-802, 1994.

[12] K. Osseo-Asare and F. J. Arriagada, "Synthesis of nanosize particles in reverse microemulsions," Ceramic Transactions, vol. 12, no. 3, pp. 3-16, 1990.

[13] L. K. Kurihara, G. M. Chow, and P. E. Schoen, "Nanocrystalline metallic powders and films produced by the polyol method," Nanostructured Materials, vol. 5, no. 6, pp. 607-613, 1995.

[14] R. Eluri and B. Paul, "Microwave assisted greener synthesis of nickel nanoparticles using sodium hypophosphite," Materials Letters, vol. 76, pp. 36-39, 2012.

[15] S. Stankovich, D. A. Dikin, G. H. B. Dommett et al., "Graphenebased composite materials," Nature, vol. 442, no. 7100, pp. 282286, 2006.

[16] Y. Zhu, S. Murali, W. Cai et al., "Graphene and graphene oxide: Synthesis, properties, and applications," Advanced Materials, vol. 22, no. 35, pp. 3906-3924, 2010.

[17] Y. Song, K. Qu, C. Zhao, J. Ren, and X. Qu, “Graphene oxide: Intrinsic peroxidase catalytic activity and its application to glucose detection," Advanced Materials, vol. 22, no. 19, pp. 22062210, 2010.

[18] M. Lv, Y. Zhang, L. Liang et al., "Effect of graphene oxide on undifferentiated and retinoic acid-differentiated SH-SY5Y cells line," Nanoscale, vol. 4, no. 13, pp. 3861-3866, 2012.

[19] W. Hu, C. Peng, W. Luo et al., "Graphene-based antibacterial paper," ACS Nano, vol. 4, no. 7, pp. 4317-4323, 2010.

[20] M. Choe, C. Y. Cho, J. P. Shim et al., "Au nanoparticle-decorated graphene electrodes for GaN-based optoelectronic devices," Physics Letters, vol. 101, no. 3, Article ID 031115, 2012.

[21] G. Eda and M. Chhowalla, "Chemically derived graphene oxide: towards large-area thin-film electronics and optoelectronics," Advanced Materials, vol. 22, no. 22, pp. 2392-2415, 2010.

[22] D. S. Sutar, G. Singh, and V. D. Botcha, "Electronic structure of graphene oxide and reduced graphene oxide monolayers," Applied Physics Letters, vol. 101, Article ID 103103, 2012.

[23] A. Benayad, H.-J. Shin, H. K. Park et al., "Controlling work function of reduced graphite oxide with $\mathrm{Au}$-ion concentration," Chemical Physics Letters, vol. 475, no. 1-3, pp. 91-95, 2009.

[24] H. Qing-Hua, X.-T. Wang, H. Chen, and Z.-F. Wang, "Synthesis of Ni/graphene sheets by an electroless Ni-plating method," New Carbon Materials, vol. 27, no. 1, pp. 35-41, 2012.

[25] Y. Zhanga, Y. Wangb, J. Jia b, and J. Wanga, "Nonenzymatic glucose sensor based on graphene oxide and electro spun $\mathrm{NiO}$ Nanofibers," Sensors and Actuators B, vol. 171-172, pp. 580-587, 2012. 
[26] S. Li, Z. Niu, X. Zhong et al., "Fabrication of magnetic Ni nanoparticles functionalized water-soluble graphene sheets nanocomposites as sorbent for aromatic compounds removal," Journal of Hazardous Materials, vol. 229-230, pp. 42-47, 2012.

[27] W. Qu, L. Zhang, and G. Chen, "Magnetic loading of graphenenickel nanoparticle hybrid for Electrochemical sensing of carbohydrates," Biosensors and Bioelectronics, vol. 42, pp. 430-433, 2013.

[28] A. V. Kabashin and M. Meunier, Recent Advances, in Laser Processing Material, Elsevier, Amsterdam, The Netherlands, 2006.

[29] J. P. Sylvestre, A. V. Kabashin, E. Sacher, M. Meunier, and J. H. T. Luong, "Stabilization and size control of gold nanoparticles during laser ablation in aqueous cyclodextrins," Journal of the American Chemical Society, vol. 126, no. 23, pp. 7176-7177, 2004.

[30] J. P. Sylvestre, A. V. Kabashin, E. Sacher, and M. Meunier, "Femtosecond laser ablation of gold in water: influence of the laser-produced plasma on the nanoparticle size distribution," Applied Physics A, vol. 80, no. 4, pp. 753-758, 2005.

[31] F. Mafuné, J. Y. Kohno, Y. Takeda, T. Kondow, and H. Sawabe, "Structure and stability of silver nanoparticles in aqueous solution produced by laser ablation," Journal of Physical Chemistry $B$, vol. 104, no. 35, pp. 8336-8833, 2000.

[32] S. Besner, A. V. Kabashin, F. M. Winnik, and M. Meunier, "Ultrafast laser based "green" synthesis of non-toxic nanoparticles in aqueous solutions," Applied Physics A, vol. 93, no. 4, pp. 955-959, 2008.

[33] A. V. Kabashin and M. Meunier, "Synthesis of colloidal nanoparticles during femtosecond laser ablation of gold in water," Journal of Applied Physics, vol. 94, no. 12, pp. 7941-7943, 2003.

[34] J. A. Balderas-Lopez, D. Acosta-Avalos, J. J. Alvarado et al., "Photoacoustic measurements of transparent liquid samples: thermal effusivity," Measurement Science and Technology, vol. 6, no. 8, pp. 1163-1168, 1995.

[35] N. M. Huang, H. N. Lim, C. H. Chia, M. A. Yarmo, and M. R. Muhamad, "Simple room-temperature preparation of high-yield large-area graphene oxide," International Journal of Nanomedicine, vol. 6, pp. 3443-3448, 2011.

[36] O. Delgado-Vasallo and E. Marin, "Application of the photoacoustic technique to the measurement of the thermal effusivity of liquids," Journal of Physics D, vol. 32, no. 5, pp. 593-597, 1999. 

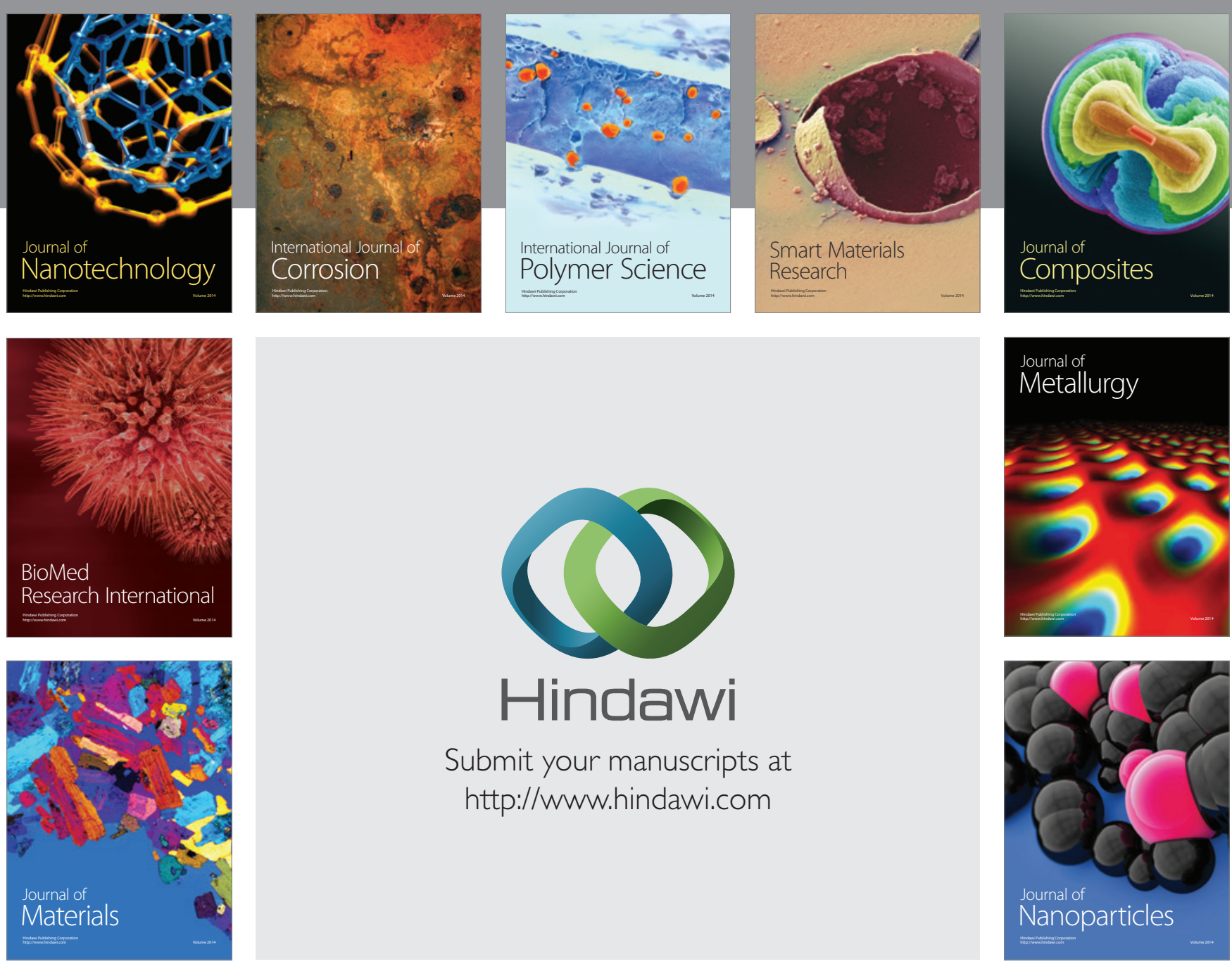

Submit your manuscripts at http://www.hindawi.com
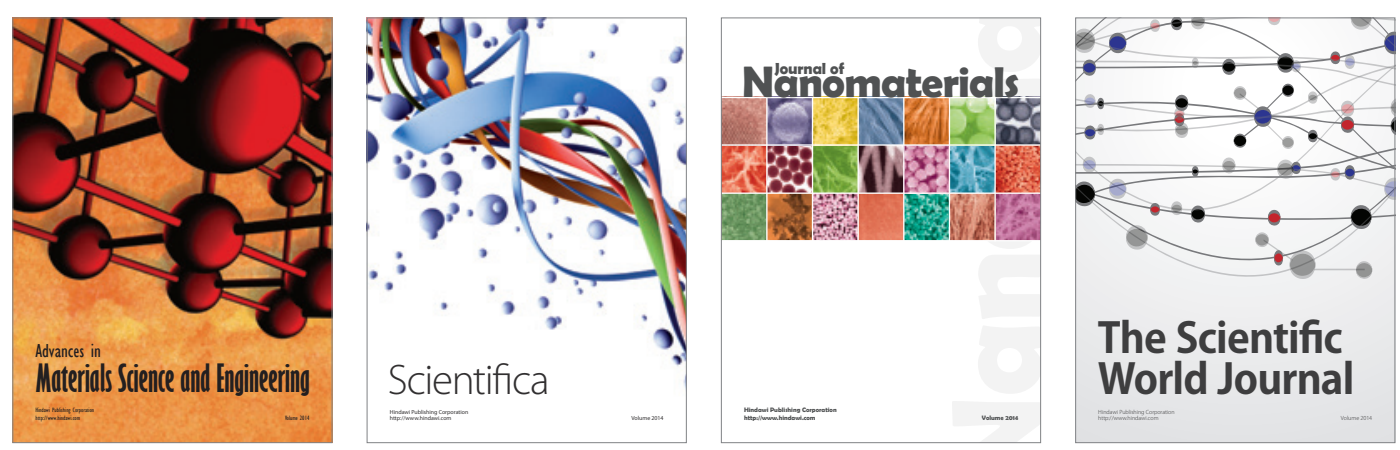

\section{The Scientific World Journal}
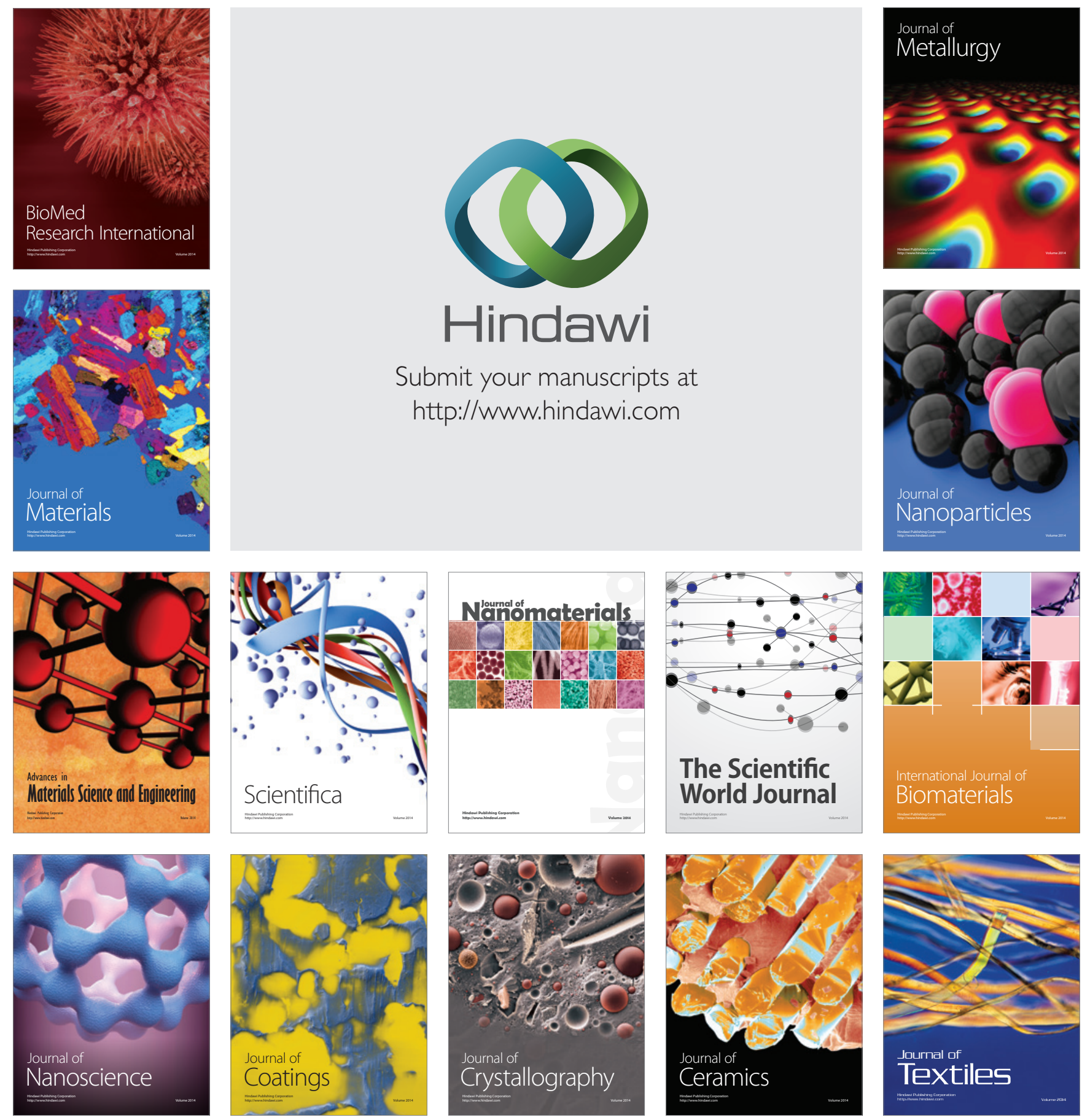